\title{
The Effect of Status on Refusal Strategies Used by American Native Speakers of English and Iranian EFL University Students
}

\author{
Amir Nikmehr (Corresponding author) \\ English Department, Faculty of Persian Literature and Foreign Languages \\ PO BOX: 516661647, University of Tabriz, Iran \\ E-mail: a_nikmehr@yahoo.com \\ Fateme Jahedi \\ Islamic Azad University, Tabriz Branch, Iran \\ PO BOX: 1666976113 \\ E-mail: fateme.jahedi@yahoo.com
}

Received: 01-03-2014

doi:10.7575/aiac.ijalel.v.3n.5p.91
Accepted: 04-05-2014

Published: 01-09-2014

URL: http://dx.doi.org/10.7575/aiac.ijalel.v.3n.5p.91

\begin{abstract}
Nowadays, the notion of pragmatics is gaining more and more prominence among language learners. Communicating merely for the sake of communication is necessary but not sufficient. In order to truly communicate, issues such as the appropriateness of speech acts and face saving become crucial. Therefore, it stands to reason to achieve a high level of pragmatic competence in speech acts. Bearing this in mind, this study opted to find out the different refusal strategies Iranian EFL students and Native American speakers employ when faced with requests from lower, equal, and higher social status interlocutors. To this end, a questionnaire was given to twenty Iranian (i.e. ten males and ten females) advanced EFL university students and twenty Native Americans via email. The results revealed that unlike American Native speakers, Iranian EFL learners have a tendency to use direct strategies of refusals more often which may be attributed to both their lack of pragmatic knowledge and interlingual transfer from their native language.
\end{abstract}

Keywords: pragmatic competence, speech acts, refusal strategies, requests, social status, interlingual transfer

\section{Introduction}

Crystal (1985) defines pragmatics as "the study of language from the point of view of users, especially of the choices they make, the constraints they encounter in using language in social interaction and the effects their use of language has on other participants in the act of communication" (p. 240). The notion of pragmatic competence was defined by Chomsky (1980, p. 224) as the "knowledge of conditions and manner of appropriate use (of the language), in conformity with various purposes". Chen (1996) believes that the pragmatic failure can cause miscommunication and as a result obstruct successful communication. Pragmatic failure may also lead to a misunderstanding of the interlocutor him/herself in cross-cultural interaction. According to Bachman (1990), it is crucial for second language learners to have knowledge of pragmatics as well as grammar and text organization to be successful in their interaction.

Due to Sadler and Eröz (2001), knowing true communicative competence is gaining more importance recently among the language learners. Achieving a high level of expertise and pragmatic competence in some speech acts such as complaints, requests, disapproval, disagreement, and refusal that are referred to as face-threatening acts is more important for learners than others to prevent them from damaging their interpersonal relationships (Brown \& Levinson, 1987). Though difficult, it's crucial for learners to gain enough knowledge of pragmatic competence (Chen 1996). In consequence, the aim of this study is to answer:

1. What refusal strategies American Native speakers and Iranian EFL university students employ?

2. Are there differences between the American Native speakers and Iranian EFL university students in their refusals under the influence of status?

3. Do Iranian EFL university students resort to interlingual transfer when they refuse in English?

\section{Review of the Literature}

\subsection{Introduction}

Finding the best ways to present oneself while simultaneously giving sufficient face to others are considered as two major elements of formal communication. Due to the governing conditions of performing communication, face can be influenced, limited, or totally lost. However one has to be careful to give full consideration to this element (i.e., face) while interacting with others (Brown \& Levinson, 1987). According to Goffman (1967), people tend to save their face mainly because of three important reasons including: the values that construct the face gain more importance in their 
opinion, the results of a certain face may create a joyful and powerful condition for them, or they find this face a useful and important element in guiding them toward higher social goals they want to achieve. People have to be cautious not to harm other's face under any circumstances at the expense of preserving their own face.

\subsection{Pragmatic transfer:}

According to Kasper (1992, p. 207) pragmatic transfer refers to "the influence exerted by learners pragmatic knowledge of languages other than the target language on their comprehension, production and learning of pragmatic information in the target language".

\subsection{The speech act of refusal}

According to Beebe, Takahashi and Uliss-Weltz (1990) request, invitation, offer and suggestion are the means by which the refusal speech act is realized. Note that in the following study, the main focus is on refusing requests. On the other hand, Zhou Geyang (2007) believes that the speech act of refusal can be initiated by itself. According to Chen, Ye, and Zhang (1995) refusal is an act by which a speaker refuses to engage in an action proposed by the interlocutor. Refusal is also defined as "a major cross-cultural sticking point for many non-native speakers" (Beebe, Takahashi, \& Uliss-Weltz, 1990, p. 56). Different factors such as gender, age, level of education, power, and social status can affect the speech act of refusal (Fraser, 1990; Smith, 1998 as cited in Wannaruk, 2008). Takahashi and Beebe (1987) state that "the inability to say 'no' clearly and politely ... has led many non-native speakers to offend their interlocutors" (p. 133).

\subsection{Refusals categorization}

Refusals are divided into two major groups based on Beebe et al.'s (1990) classification, which are direct and indirect refusals. The direct refusals consist of non-performatives such as, "no" and performative verbs like "I can't" while the indirect ones have a richer variety. Beebe $(1990$, p. 62) has provided the following classification due to indirect refusals:

"1. Statement of regret like: I'm sorry

2. Wish like: I wish I could help you

3. Excuse, reason, explanation like: I have an exam

4. Statement of alternative

5. Set condition for future or past acceptance like: If I had enough money

6. Promise of future acceptance like: I'll do it next time

7. Statement of principle like: I never drink right after dinner

8. Statement of philosophy like: One can't be too careful

9. Attempt to dissuade the interlocutor:

10. Threat or statement of negative consequences to the requester like: If I knew you would judge me like this I would have never done that

11. Criticize the requester like: It's a silly suggestion

12. Guilt trip (waiter to customers who want to sit for a while) like: I can't make a living off people who just order tea

13. Acceptance functioning as a refusal:

13.1. Unspecific or indefinite reply like: I don't know when I can give them to you

13.2. Lack of enthusiasm like: I'm not interested in diets

14. Avoidance:

14.1. Non-verbal (silence, hesitation, doing nothing and physical departure)

14.2. Verbal (topic switch, joke, repetition of past request, postponement and hedge); an example for postponement can be like: I'll think about it

There are also some adjuncts to the refusals as follows:

15. Statement of positive opinion like: That's a good idea

16. Statement of empathy like: I know you are in a bad situation

17. Pause fillers like: well and uhm

18. Gratitude/ appreciation like: Thank you".

\subsection{Previous studies}

Beebe et al. (1990) carried out one of the major studies on refusals. The subjects involved in this study were Japanese learners of English in which they were investigated due to their pragmatic transfer of performing the refusal speech act. A Discourse Completion Test consisting of four categories, that is, requests, invitations, offers, and suggestions designed on the basis of the social variable (i.e., lower, equal, \& higher) was used to collect data. The results obtained based on the analysis of the frequency of the Japanese learners' responses indicated that there was evidence of pragmatic transfer from the learners native language. 
In another interesting study, Nelson, Al Batal, and EL Bakary (2002) considered American and Egyptian learners' thoughts due to their beliefs in refusing based on: strategy, directness level, social status and gender. Thirty Americans and 25 Egyptians participated in the study. The subjects were required to respond verbally to a modified version of DCT instead of writing answers. The results indicated that both the Egyptian and American participants' responses were similar, although the Americans refused more frequently. The two most frequent refusal strategies used were reasons and negative willingness.

King and Silver (1993) studied the impact of teaching sociolinguistic variables on non-native refusal strategies. When the results of the post-test were compared with the pretest Discourse Completion Questionnaire (DCQ) data, no significant effect due to instruction was present. However many studies have supported the opposite, that is, instruction can prove to be effective to some extent on non-native refusal strategies.

In his study on refusal speech acts, Al-Kahtani (2005), assumed people from different cultural backgrounds perform refusals differently even while using the same linguistic code (i.e. English). The way Americans, Arabs and Japanese perform refusals were compared. The aim of this study was to point out the differences in realizing speech acts of refusals in different cultures and problems posed to L2 learners when producing speech acts in the target language. Lauper (1997) carried out a study with 60 English native speakers and 120 Spanish speakers, half of which responded in English and the other half in Spanish. Responses on a questionnaire consisting of 20 different situations indicated that most of the Spanish speakers employed the same refusal strategies in both English and their native language (that is, Spanish) thus giving support to the notion of pragmatic transfer.

\subsection{Significance}

A significant milestone of applied linguistics is the study of cross-cultural communication, which is a conspicuous element in both language learning and language teaching and must be studied in a scientific fashion. This scientific approach has the merit of making cross-cultural interactions even more tangible. In every day communication people may inevitably need to reject a request, which is easier said than done considering the circumstances that may lead to taking offense on the interlocutor's part. This being the case, it seems that pragmatic knowledge is quite essential as is linguistic knowledge. Based on the concepts discussed, the study on hand puts emphasis on the social status (low, high, and equal) variable that controls the way people deal with the act of refusing in their daily conversations.

\section{Methodology}

\subsection{Subjects}

The questionnaire was given to twenty Iranian (i.e. ten males and ten females) advanced EFL university students and twenty Americans again with ten males and ten females to complete the tasks via email. It should be noted that the reason for distributing the questionnaire to an equal number of males and females, is to rule out the possible moderator variable of gender.

\subsection{Instrumentation and Procedures}

The subjects were to complete a Discourse Completion Test (DCT) which was developed by Beebe, Takahashi, and Uliss-Weltz (1990). This instrument was chosen because it allowed for intercultural comparison as it can be administered to a large number of participants in a non-elaborative time frame. Moreover, it allowed the researcher to have complete control over the different contextual variables (Blum-Kulka, House \& Kasper, 1989). Furthermore, the situations developed by Beebe et al. (1990) had already been piloted and checked for reliability. The test consisted of three contexts where the subjects need to refuse through written role play. In addition, the contexts given to the subjects are based on different statuses: higher, equal, and lower. Each of the three situations required a refusal, that is, one refusal to a person of higher status, one to a person of equal status, and one to a person of lower status. Following the data collection, the utterances were codified based on a classification of refusal strategy adopted from Beebe, Takahashi, \& Uliss-Weltz (1990).

Rose (2002), points out that this instrument indicates which particular forms and strategies learners choose to employ in a given situation. Thus, the authors claim that although not comparable to face-to-face interaction, it can provide pertinent information regarding learners' knowledge on the specific pragmatic feature under study. In fact, Kasper (2000, p. 329) indicates that "DCT is an effective data collection instrument when the objective of the investigation is to inform the speakers' pragmalinguistic knowledge of the strategic and linguistic forms by which communicative acts can be implemented, and about their sociopragmatic knowledge of the context factors under which particular strategies and linguistic choices are appropriate".

\section{Data analysis and results}

The obtained data were analyzed based on the sequences of semantic formula with Beebe's (1990) classification of refusal strategies as the criteria of analysis. It's worth mentioning that according to Cohen (1996, p. 265) "A semantic formula refers to a word, phrase, or sentence that meets a particular semantic criterion or strategy, any one or more of these can be used to perform the act in question". Consider an example taken from Beebe (1990, p. 57) "if a participant had to refuse an invitation to a friend's house for dinner by saying: I'm sorry, I already have plans, Maybe next time, this was coded as: I'm sorry [statement of regret], I already have plans [excuse], May be next time [statement of alternative]" 
When all the data were coded into semantic formulas and a high level of reliability was achieved, descriptive statistics were used to analyze the data. The following table reveals the overall frequency of each refusal strategy to requests, used by native and non-native speakers.

Table 1.Overall Frequency of Iranian EFL University Students and American Native Speakers' Refusal Strategy use in response to Requests

\begin{tabular}{|c|c|c|c|c|c|c|}
\hline \multirow{2}{*}{ Context \& Status } & \multicolumn{7}{|c|}{ Request } \\
\cline { 2 - 7 } & Lower Status & \multicolumn{2}{|c|}{ Equal Status } & \multicolumn{2}{c|}{ Higher Status } \\
\cline { 2 - 7 } & NS & NNS & NS & NNS & NS & NNS \\
\hline Perfusal Strategies & - & 35 & 7 & 24 & - & 26 \\
\hline Non-performative & 12 & 47 & 3 & 34 & - & 22 \\
\hline Statement of regret & 24 & 12 & 36 & 17 & 45 & 47 \\
\hline Wish & 11 & 3 & 19 & 7 & 34 & 33 \\
\hline Excuse, reason, explanation & 39 & 8 & 47 & 12 & 48 & 23 \\
\hline Statement of alternative & 31 & 2 & 35 & 4 & 36 & 7 \\
\hline Condition for future or past acceptance & 5 & - & 15 & 3 & 44 & - \\
\hline Promise of future acceptance & 7 & - & 9 & 6 & 37 & 8 \\
\hline Statement of principle & 3 & - & - & - & - & - \\
\hline Statement of philosophy & 16 & - & 5 & - & 13 & - \\
\hline Attempt to dissuade interlocutor & 9 & - & 7 & 2 & - & 3 \\
\hline Acceptance that functions as a refusal & - & - & 5 & - & 8 & - \\
\hline Avoidance & - & 23 & - & 14 & - & 12 \\
\hline Adjuncts to refusals & 2 & 47 & 7 & 49 & 21 & 55 \\
\hline
\end{tabular}

The most conspicuous point drawn from the table above is that native speakers most frequently resort to the indirect refusal strategy of excuse, reason, and explanation regardless of the interlocutor's status. However with higher status, the frequency use of excuse, reason, and explanation increases. On the other hand, results are not so straightforward when coming to the non-native group. As can be seen, they most frequently use both direct non-performatives and adjuncts in refusal to a request from a lower-status interlocutor, while the strategy adjuncts to refusals is the most preferred option to a request from both an equal and higher status interlocutor.

In order to provide a better picture due to each status, frequencies have been illustrated by the following bar graphs, which in turn have been converted into percentages presented in a pie chart fashion for convenience. Based on the following pie charts, the top three strategies employed by NSs and NNSs according to each interlocutor status (i.e., lower, equal, higher) are ranked.

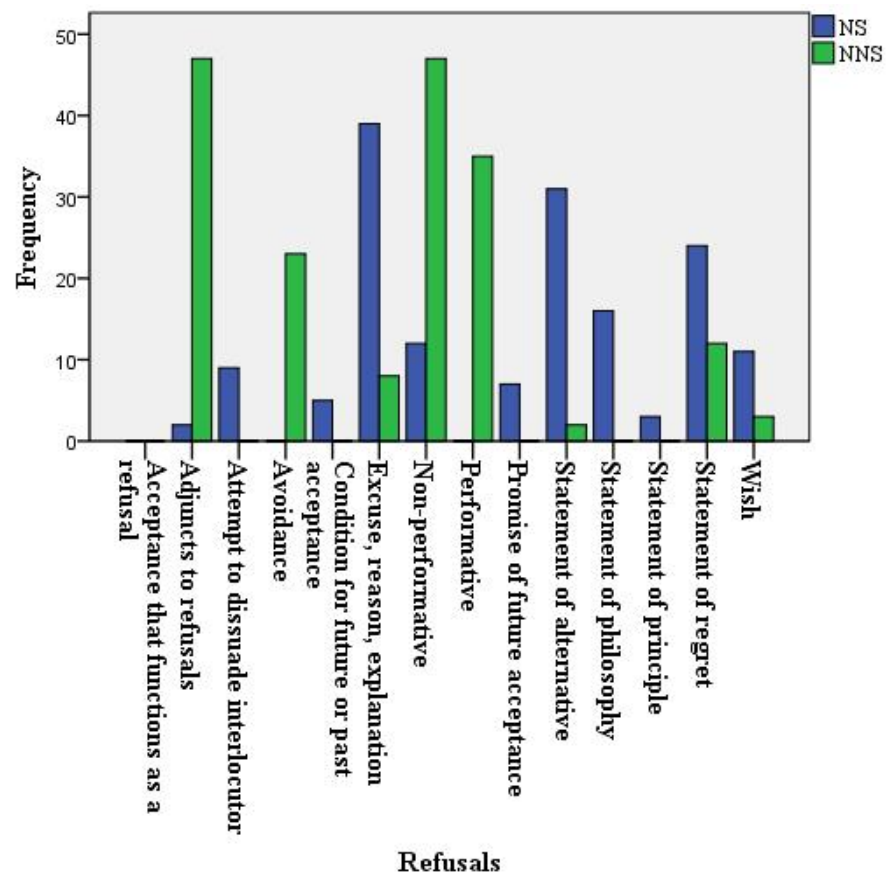

Figure 1.Frequency of Refusal strategy use by Native and Non-Native speakers in Response to Requests from Lower Status 


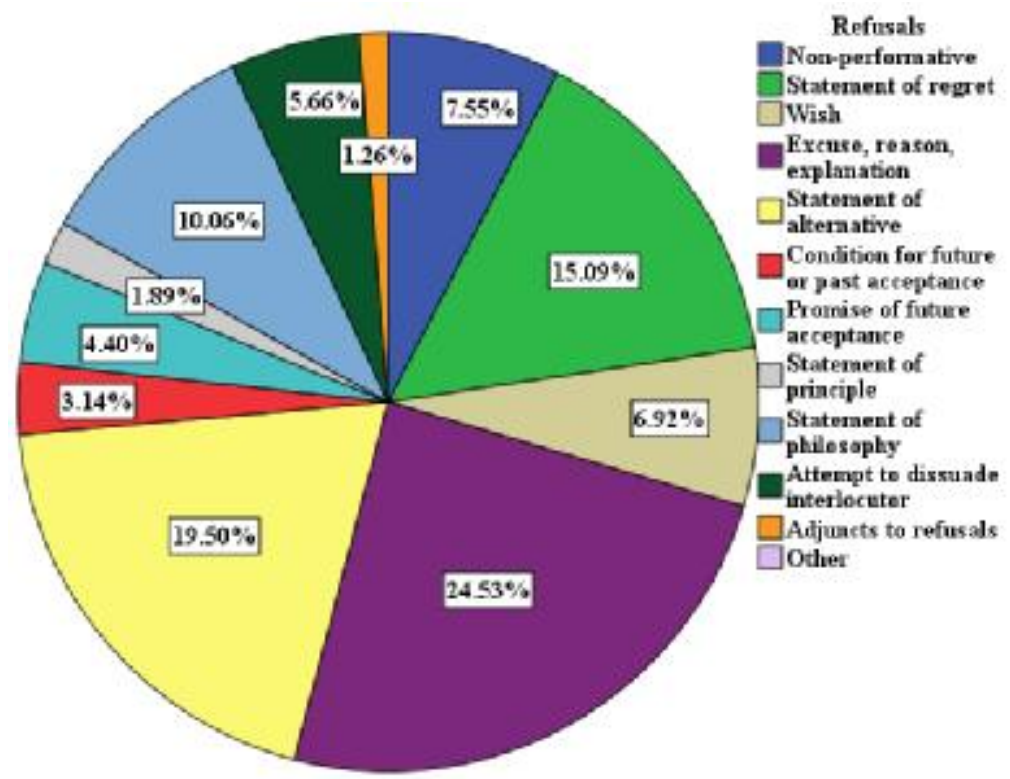

Figure 2.Distribution of Refusal Strategy use by Native speakers in response to Requests from Lower Status

As can be seen from Figure.2, the most common strategies used by NSs when confronted with a request from a lower status interlocutor are first excuse, reason, and explanation(24.53\%), followed by the statement of alternative refusal strategy $(19.50 \%)$, and then the statement of regret strategy $(15.09 \%)$.

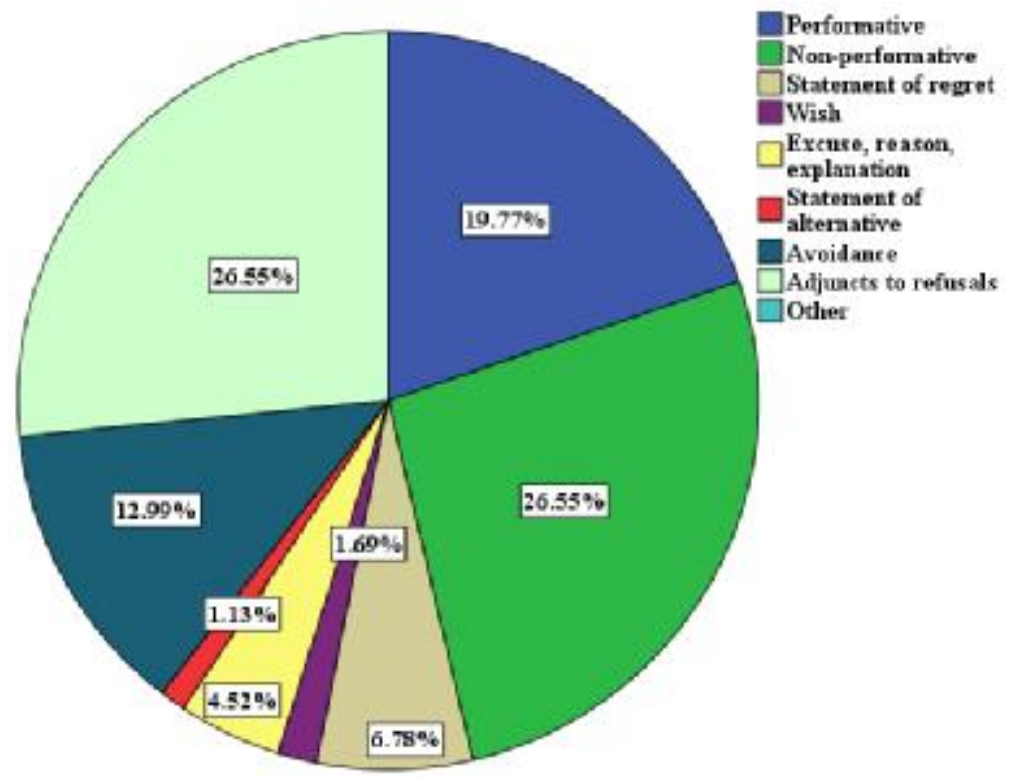

Figure 3.Distribution of Refusal Strategy use by Non-Native speakers in Response to Requests from Lower Status

According to Figure 3, the most preferred refusal strategies used by the non-native group in response to a lower status interlocutor are: direct non-performatives and adjunct to refusals $(26.55 \%)$, followed respectively by performatives $(19.77 \%)$ and avoidance $(12.99 \%)$. 


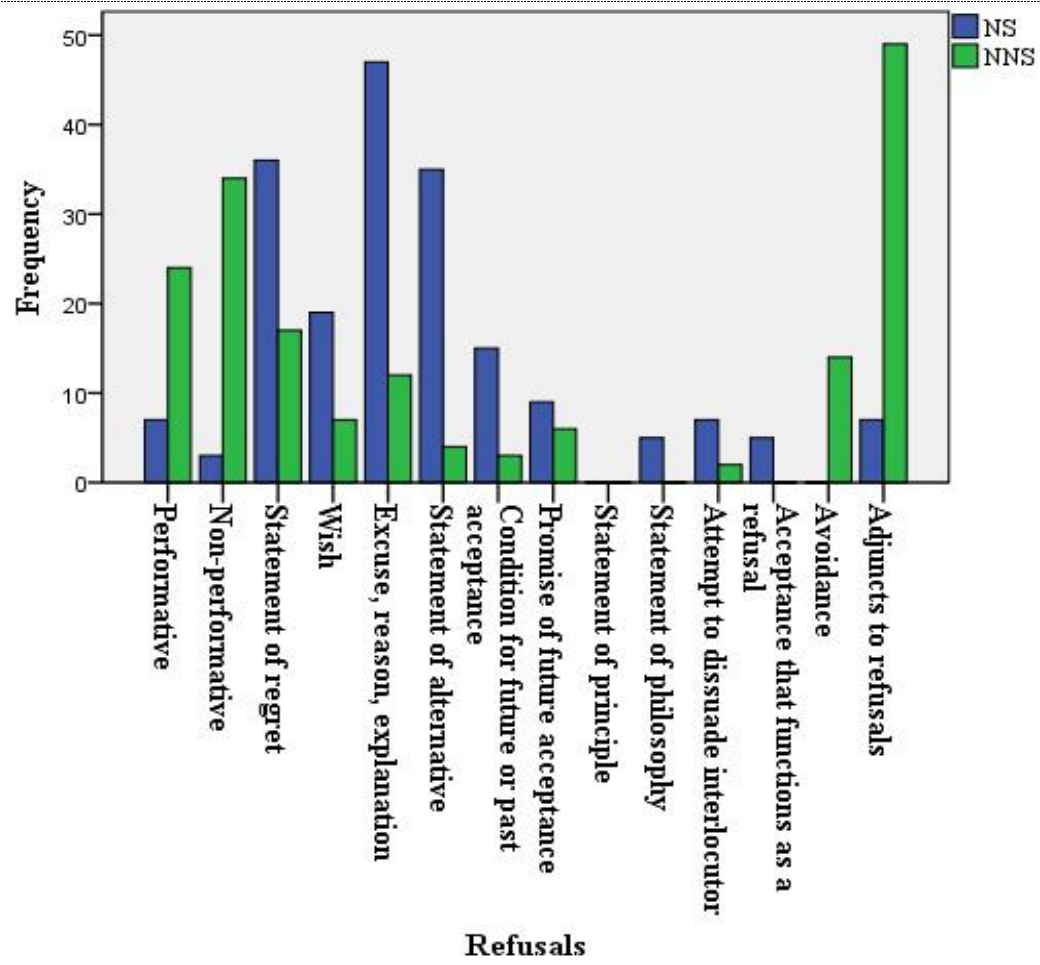

Figure 4.Frequency of Refusal Strategy use by Native and Non-Native speakers in Response to Requests from Equal Status

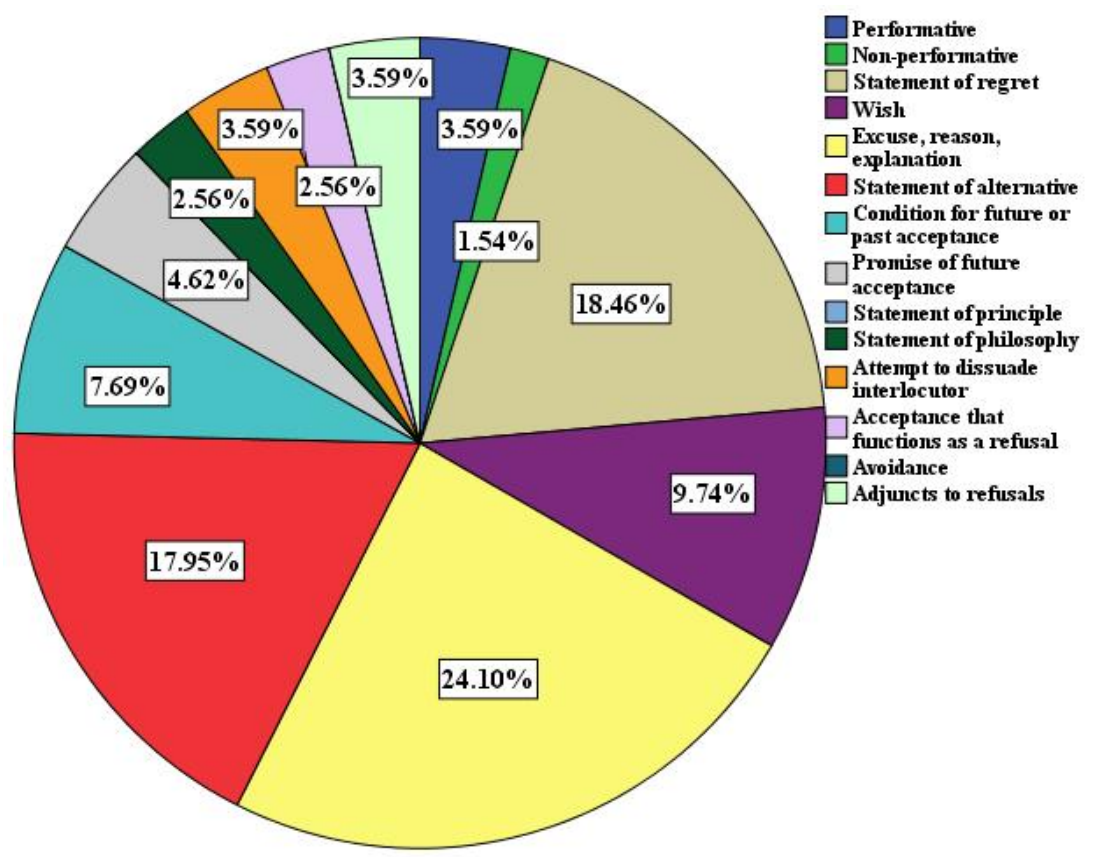

Figure 5.Distribution of Refusal Strategy use by Native speakers in Response to Requests from Equal Status

Figure 5 indicates that the top three strategies used by the NS group are: excuse, reason, and explanation (24.10\%); statement of regret (18.46\%); and statement of alternative (17.95\%). 


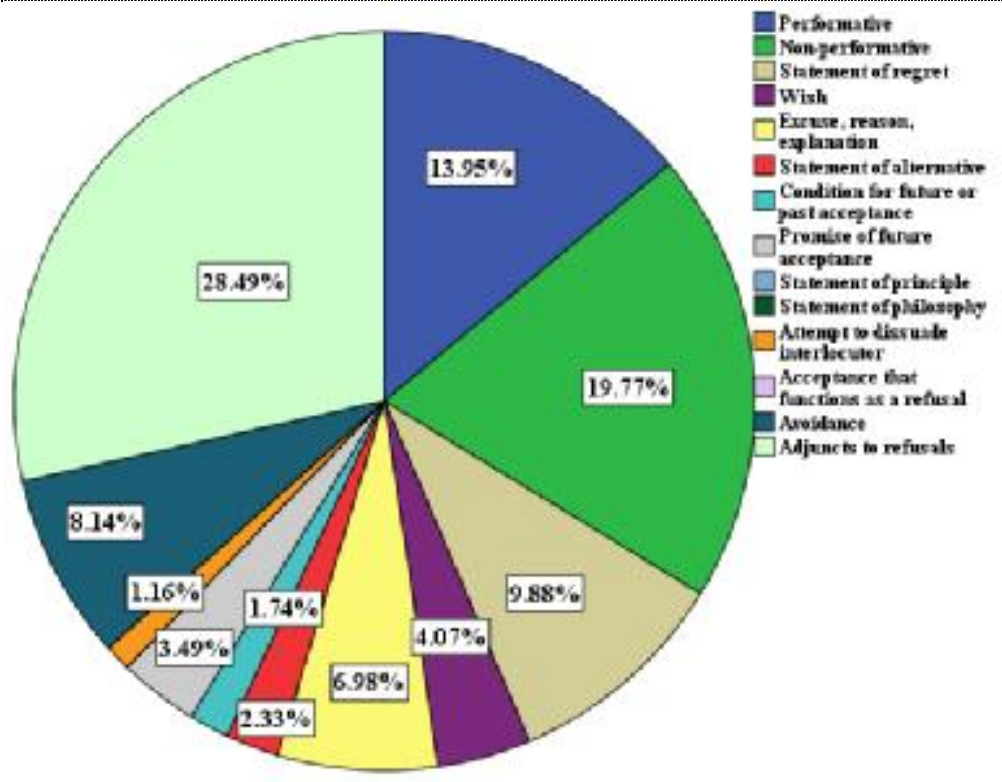

Figure 6.Distribution of Refusal Strategy use by Non-Native speakers in Response to Requests from Equal Status

According to Figure 6 the NNS group employed the strategies: adjuncts to refusals (28.49\%), non-performatives $(19.77 \%)$, and avoidance (13.95\%) when refusing requests from equal status interlocutors.

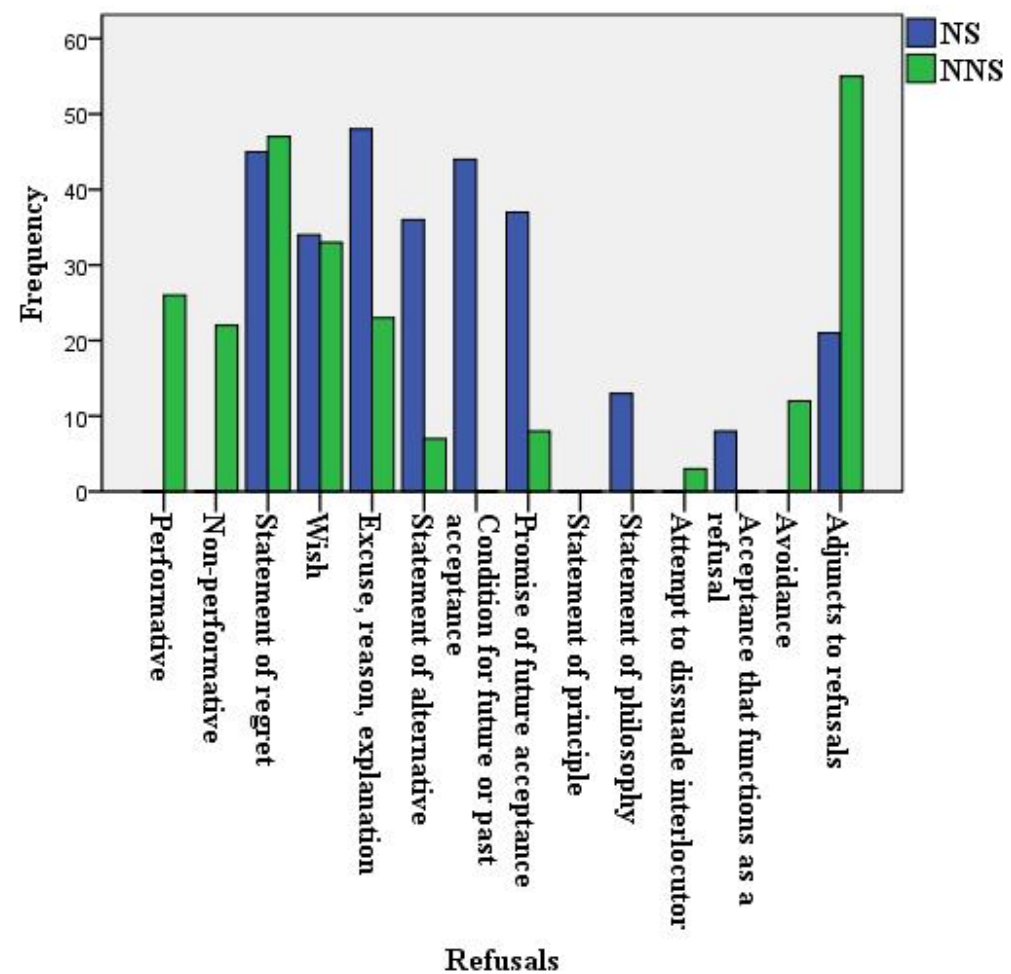

Figure 7. Frequency of Refusal strategy use by Native and Non-Native speakers in Response to Requests from Higher Status 


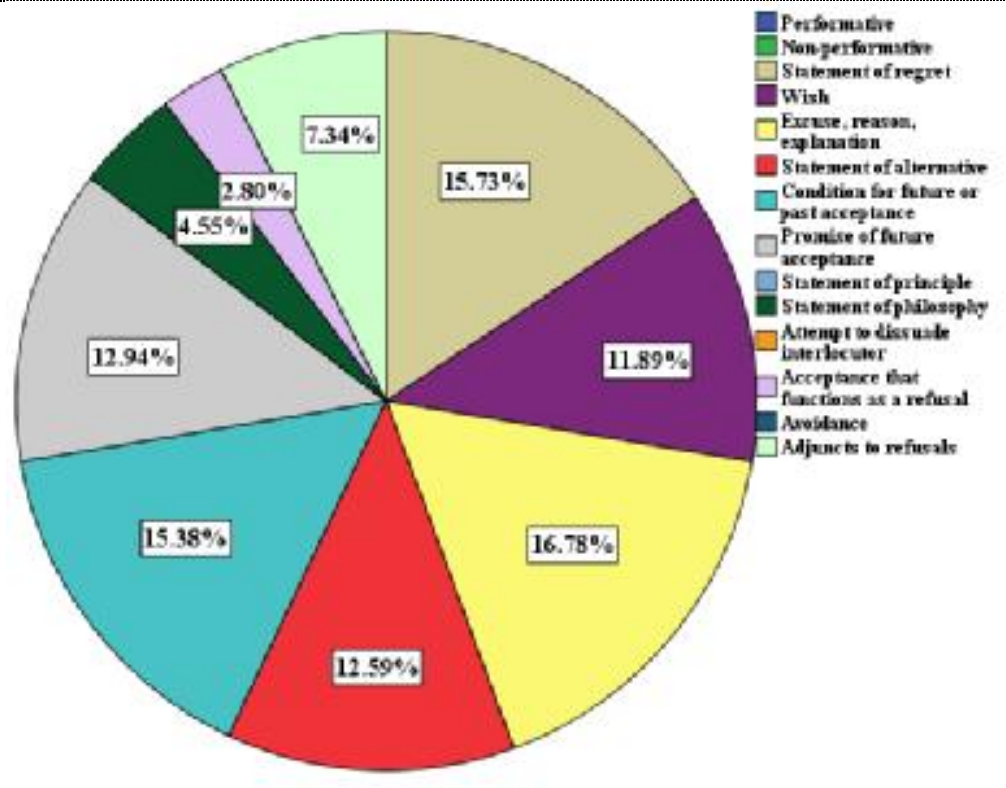

Figure 8.Distribution of Refusal Strategy use by Native speakers in Response to Requests from Higher Status

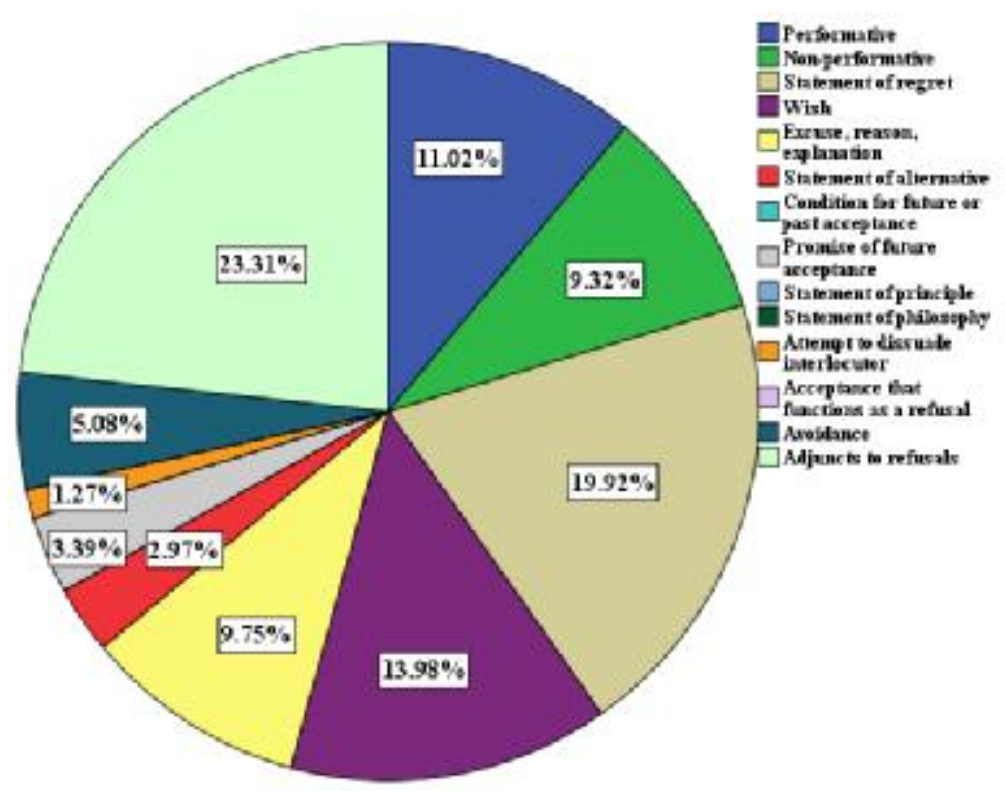

Figure 9.Distribution of Refusal Strategy use by Non-Native speakers in Response to Requests from Higher Status

Figures 8 and 9 reveal the top three refusal strategies in a higher status context with the NS group employing: Excuse, reason, and explanation (16.78\%), statement of regret $(15.73 \%)$ and condition for future or past acceptance $(15.38 \%)$ respectively while the NNS group uses: Adjuncts to refusals (23.31\%), statement of regret (19.92\%), and wish $(13.98 \%)$.

\section{Conclusion}

Data analysis may show contrastive use of refusal strategies amongst Iranian and American respondents. Due to the obtained results, it seems that Iranian EFL learners have a tendency to use direct strategies of refusals more often which may be attributed to both their lack of pragmatic knowledge and interlingual transfer from their native language. However, one interesting finding is that, when confronted with a request from a higher status interlocutor, both natives and non- natives resort to the statement of regret strategy by means of expressions such as, 'I'm sorry' or 'I feel terrible'. It may be the case that formalities are taken much more seriously in the Iranian culture than in the American culture, which explains the use of the 'wish' refusal strategy by Iranians in the higher status context due to pragmatic interlingual transfer.

The point worth mentioning is that Iranian EFL learners study refusals from a mere grammatical viewpoint, rather than a pragmatic one. They do not distinguish the means of refusing to people of higher, equal or lower status. This is particularly why they employ almost the same refusal strategies regardless of the interlocutor's status. They are not trained enough to use refusal strategies to preserve good relations with offended people. Moreover, they do not study 
the sincerity and length of their responses. Having said all this, we have to bear in mind that pragmatic competence does not progress spontaneously; therefore it must be taught and focused on.

\section{References}

Al-Kahtani, W. (2005). Refusal realizations in three different cultures: a speech act theoretically based cross-cultural Study. Journal of King Saud Univ. 18, 35-57.

Bachman, L. (1990). Fundamental considerations in language testing. Oxford: Oxford University Press.

Beebe, L. M., Takahashi, T., \& Uliss-Weltz, R. (1990). Pragmatic transfer in ESL refusals. In R. C. Scarcella, E. S. Andersen, \& S. D. Krashen (Ed.), Developing communicative competence in second language (55-73). New York: Newbury House.

Brown, P., \& Levinson, S. (1987). Politeness: some universals in language usage. Cambridge: Cambridge University Press.

Blum-Kulka, S., \& House, J. (1989). Cross-cultural and situational variation in requesting behavior. In S. Blum-Kulka, J. House, \& G. Kasper (Ed.), Cross-cultural pragmatics: Requests and apologies (123-154). Norwood, NJ: Ablex.

Chen, H. J. (1996). Cross-cultural comparison of English and Chinese metapragmatics in refusal. Indiana University.

Chen, X., Ye, L. \& Zhang, Y. Y. (1995). Refusing in Chinese. In G. Kasper (Eds.), Pragmatics of Chinese as Native and Target Language (119-163). Manoa, HI: University of Hawaii Press.

Chomsky, N. 1980: Rules and representations. New York: Columbia University Press.

Cohen, A. D. (1996). Developing the ability to perform speech acts. Studies in Second Language Acquisition, 18, 253267.

Crystal, D. (1985). A dictionary of linguistics and phonetics. (2nd. Ed.). Oxford: Blackwell.

Geyang, Z. (2007). A pilot study on refusal to suggestions in English by Japanese and Chinese EFL learners. Hiroshima: Hiroshima University Press.

Goffman, E. (1967). Interaction ritual: essays on face-to-face behavior. New York: Pantheon Books.

Kasper, G. (1992). Pragmatics transfer. Second Language Research, 8, 203-231.

Kasper, G, (2000). Data collection in pragmatics research: In Culturally Speaking: Managing Rapport through Talk across Cultures ,H. Spencer-Oatey (ed.), 316-360. London: Continuum.

King, K. \& Silver R. (1993). "Sticking points": Effects of instruction on NNS refusal strategies. ERIC Document Reproduction Service, 3, 59-74.

Lauper, J. (1997). Refusal strategies of native Spanish speakers in Spanish and English and of native English speakers in English. Paper presented at the Annual Meeting of the Teachers of English to Speakers of Other Languages.

Nelson, G., Al Batal, M. \& EL Bakary, W. (2002). Directness vs. indirectness: Egyptian Arabic and US English communication style. International Journal of Intercultural Relations, 26 (1), 39-57.

Sadler, R. W. \& Eröz, B. (2001). "I refuse you!" An examination of English refusals by native speakers of English, Lao, and Turkish. Arizona Working Papers in SLA, 9, 53-80.

Takahashi, T., \& Beebe, L. M. (1987). The development of pragmatic competence by Japanese learners of English. JALT Journal, 8 (2), 131-155.

Wannaruk, A. (2008). Pragmatic transfer in Thai EFL refusals. RELC Journal, 39, 318-337.

http://dx.doi.org/10.1177/0033688208096844. 